\title{
Inclusion of ecologically based trait variation in plant functional types reduces the projected land carbon sink in an earth system model
}

\author{
LIENEKE M. VERHEIJEN ${ }^{1}$, RIEN AERTS ${ }^{1}$, VICTOR BROVKIN ${ }^{2}$, JEANNINE CAVENDER- \\ BARES ${ }^{3}$, JOHANNES H. C. CORNELISSEN ${ }^{1}$, JENS KATTGE ${ }^{4}$ and PETER M. VAN BODEGOM ${ }^{1,5}$ \\ ${ }^{1}$ Systems Ecology, Department of Ecological Science, VU University Amsterdam, De Boelelaan 1085, 1081 HV Amsterdam, The \\ Netherlands, ${ }^{2}$ Max Planck Institute for Meteorology, Bundesstrasse 55, 20146 Hamburg, Germany, ${ }^{3}$ Department of Ecology, \\ Evolution and Behavior, University of Minnesota, Saint Paul, MN 55108, USA, ${ }^{4}$ Max Planck Institute for Biogeochemistry, Hans \\ Knoell Strasse 10, 07745 Jena, Germany, ${ }^{5}$ Institute of Environmental Sciences, Leiden University, Einsteinweg 2, 2333 CC, Leiden, \\ The Netherlands
}

\begin{abstract}
Earth system models demonstrate large uncertainty in projected changes in terrestrial carbon budgets. The lack of inclusion of adaptive responses of vegetation communities to the environment has been suggested to hamper the ability of modeled vegetation to adequately respond to environmental change. In this study, variation in functional responses of vegetation has been added to an earth system model (ESM) based on ecological principles. The restriction of viable mean trait values of vegetation communities by the environment, called 'habitat filtering', is an important ecological assembly rule and allows for determination of global scale trait-environment relationships. These relationships were applied to model trait variation for different plant functional types (PFTs). For three leaf traits (specific leaf area, maximum carboxylation rate at $25^{\circ} \mathrm{C}$, and maximum electron transport rate at $25^{\circ} \mathrm{C}$ ), relationships with multiple environmental drivers, such as precipitation, temperature, radiation, and $\mathrm{CO}_{2}$, were determined for the PFTs within the Max Planck Institute ESM. With these relationships, spatiotemporal variation in these formerly fixed traits in PFTs was modeled in global change projections (IPCC RCP8.5 scenario). Inclusion of this environment-driven trait variation resulted in a strong reduction of the global carbon sink by at least $33 \%\left(2.1 \mathrm{Pg} \mathrm{C}^{\mathrm{yr}}{ }^{-1}\right.$ ) from the 2nd quarter of the 21st century onward compared to the default model with fixed traits. In addition, the mid- and high latitudes became a stronger carbon sink and the tropics a stronger carbon source, caused by trait-induced differences in productivity and relative respirational costs. These results point toward a reduction of the global carbon sink when including a more realistic representation of functional vegetation responses, implying more carbon will stay airborne, which could fuel further climate change.
\end{abstract}

Keywords: assembly theory, carbon cycle, climate-vegetation feedbacks, DGVM, ESM, NEE, plant traits, projection, trait variation, trait-environment relationships

Received 29 August 2014 and accepted 6 January 2015

\section{Introduction}

Global change projections by different earth system models (ESMs) diverge strongly in their predicted terrestrial global carbon budgets, both in the magnitude and direction of change. Differences between ESMs in projected changes in land carbon storage range from about 300 to $600 \mathrm{Pg}$ carbon around 2100, depending on the climate change scenario (Jones et al., 2013). One of the causes of variation among projections is that the modeled functional responses of ecosystems, for example, the responses of vegetation productivity and autotrophic respiration to climate drivers, differ strongly

Correspondence: Lieneke M. Verheijen, tel. + 3120 5986989, fax +31 20 5987123, e-mail: 1.m.verheijen@vu.nl among models (Sitch et al., 2008). In addition, lack of inclusion of vegetation dynamics (Poulter et al., 2010) and of vegetation adaptation to changing environments (Sitch et al., 2008) are thought to contribute to these large intermodel deviations in global carbon budgets around 2100.

In part, the limited variation in the functional responses of vegetation within most dynamic global vegetation models (DGVMs, which represent the land surface component, including vegetation dynamics, in ESMs) is caused by representing the vast range of vascular plant species by only a small number of static plant functional types (PFTs) (Van Bodegom et al., 2012; Pavlick et al., 2013). PFTs tend to be parameterized with a number of PFT-specific static properties, related to, for example, phenology and photosynthesis, 
allowing for only limited variation in vegetation behavior within PFTs. In reality, it is well-known that vegetation responses to the environment are caused by environmental drivers working via multiple processes at different temporal and spatial scales, including plasticity, acclimation, and (genotypic) adaptation in physiological and morphological traits (Shaw \& Etterson, 2012), and, at the community scale, via shifts in species abundance and species turnover. In most current DGVMs, however, PFTs do not allow for such withinPFT dynamics, because the mechanisms underlying functional responses to environmental change are not or superficially modeled. Moreover, these functional responses of vegetation communities to environmental change also modify ecosystem functioning and the vegetation feedbacks to the environment (Lavorel \& Garnier, 2002; Diaz et al., 2004). Consequently, the lack of variation in traits in PFTs in most DGVMs may introduce inaccuracies in model predictions (Groenendijk et al., 2011).

In response to environmental change, mean trait values of plant communities vary. Such change in traits may be determined by ecological community assembly rules, which express the impacts of 'habitat filtering' (Keddy, 1992; Cornwell et al., 2006; Gotzenberger et al., 2012), where the local environment constrains the viable species' trait ranges in a community. For many traits, global trait-environment relationships have already been identified (Wright et al., 2005; Ordoñez et al., 2009; Douma et al., 2012b; Van Ommen Kloeke et al., 2012). Such relationships are used to predict community mean trait values and thereby PFT distribution and species assemblages (Douma et al., 2012a; Van Bodegom et al., 2014). Using community mean traits, variation in functional vegetation responses can be modeled within PFTs based on ecological theory, but without needing to invoke mechanistic processes that are not fully quantified or understood. By quantifying the relationships between observed variation in community mean traits and their environmental drivers and incorporating these into DGVMs, traits can be adjusted every year within the model, allowing for spatial and temporal variation in functional responses of vegetation to environmental change and modification of vegetation-atmosphere feedbacks.

Equilibrium simulations based on this approach have shown very strong impacts on carbon fluxes and vegetation distribution (Verheijen et al., 2013), but the impact in global change projections is unknown. Because the response of the community may be different from that expected from single species responses (Poorter \& Navas, 2003) and changes in community mean trait values include both within-species changes as well as changes induced by differences in species abundances, the mag- nitude and direction of community-level responses, and related carbon fluxes are difficult to foretell. Therefore, the aim of this study was to identify whether and how the global carbon budget is modified in space and time in global change projections when multiple environmental sources of variation in functional vegetation responses are included.

We implemented trait variation within the DGVM component of the Max Planck Institute Earth System Model (MPI-ESM). Three leaf traits that have been static in the model so far were selected. These traits were specific leaf area (SLA, fresh leaf area per dry mass), maximum carboxylation rate at a reference temperature of $25{ }^{\circ} \mathrm{C}\left(V_{\mathrm{cmax}_{25}}\right)$, and maximum electron transport rate at $25{ }^{\circ} \mathrm{C}\left(J_{\max _{25}}\right)$. Photosynthetic parameters are the most sensitive parameters of DGVMs (White et al., 2000; Zaehle et al., 2005) and varying such traits are likely to modify model performance upon global change. For these three traits, for each PFT in the model, relationships with the environment were determined. In the model, these traits were reparameterized on a yearly basis depending on local environmental conditions of the previous year, allowing vegetation to respond dynamically to the environment. Projections were run separately with default static traits and variable traits, each with two simulations, one with climate and atmospheric $\mathrm{CO}_{2}$ change and one with climate change with atmospheric $\mathrm{CO}_{2}$ kept at pre-industrial concentrations, to disentangle trait impacts on modified vegetation responses and carbon fluxes with and without the inclusion of $\mathrm{CO}_{2}$ fertilization of photosynthesis.

\section{Materials and methods}

\section{Model description}

The MPI-ESM was developed by the Max Planck Institute for Meteorology (Germany). Fluxes of water, carbon, and energy between land and atmosphere, as well as vegetation dynamics are simulated by the DGVM JSBACH (Raddatz et al., 2007; Brovkin et al., 2009; Reick et al., 2013) which is the land surface component of the MPI-ESM. In JSBACH, grid cells are covered with different fractions of PFTs. In this setup of JSBACH, 8 PFTs were present: tropical broad-leaved evergreen trees, tropical broad-leaved deciduous trees, extratropical (both temperate and boreal) evergreen trees, extratropical deciduous trees, raingreen shrubs, cold/deciduous shrubs, C3 grasses, and C4 grasses. Competition between woody (shrubs and trees) and nonwoody classes (grasses) is based on different rates of establishment into unoccupied land. Within woody or nonwoody vegetation types, competition is based on multiyear net primary productivity (NPP). Mortality is natural (fractional decline) or disturbance induced (by windbreaks or fire). In this setup, no anthropogenic impacts were modeled, meaning crops were not included, and there was no land-use 
change. The setup did not include a nitrogen cycle either as this was not available for this coupled model setup at the time of the simulations.

Based on the availability of georeferenced observational trait data, needed to determine the relationships between traits and environmental conditions, three originally PFT-specific parameters could be selected to vary: SLA $\left(\mathrm{m}^{2} \mathrm{~kg}^{-1}\right.$ carbon), $V_{\mathrm{cmax}_{25}}\left(\mu \mathrm{mol} \mathrm{m} \mathrm{m}^{-2} \mathrm{~s}^{-1}\right)$, and $J_{\max _{25}}\left(\mu \mathrm{mol} \mathrm{m} \mathrm{m}^{-2} \mathrm{~s}^{-1}\right)$. Although in the simulation with trait variation spatial and temporal variation in these traits occurred, the functional roles of the traits remained the same as in the default simulations. For an elaborate description of these functional roles of these traits in JSBACH, see Verheijen et al. (2013) and its supplementary material. In short, $V_{\mathrm{cmax}_{25}}$ and $J_{\max _{25}}$ are reference values used in the photosynthesis routine [based on Farquhar (1988) and Farquhar et al. (1980) for C3 plants and Collatz et al. (1992) for C4 plants] to calculate $V_{\text {cmax }}$ and $J_{\max }$ at ambient temperatures and subsequently actual carboxylation and electron transport rate. Leaf carbon assimilation $(A)$ is then determined by the lower value of the actual carboxylation and electron transport rate minus leaf maintenance (dark) respiration $\left(R_{\mathrm{d}}\right)$. Ambient $R_{\mathrm{d}}$ is derived from $R_{\mathrm{d}}$ at a reference temperature of $25^{\circ} \mathrm{C}\left(R_{\mathrm{d}, 25}\right)$, which is a constant fraction of $V_{\text {max }_{25}}$.

Gross primary productivity (GPP) is obtained when A is scaled to the canopy by the leaf area index (LAI). NPP is GPP minus whole plant maintenance respiration $\left(R_{\mathrm{m}}\right.$, which scales up from leaf $\left.R_{\mathrm{d}}\right)$ and growth respiration $\left(R_{\mathrm{g}}\right.$, which is a fixed portion of GPP- $R_{m}$ ). Within a PFT, NPP is divided in fixed fractions over different carbon pools: aboveground and belowground 'green' (resource acquisition) pools (leaves and fine roots), wood pools, reserve pools, and root exudates. SLA plays no role in determining LAI, but controls, together with LAI, the maximum quantity of carbon in the green pool and the optimal quantity of carbon in the reserve pool, thus codetermining the flow of carbon to the litter pools via modification of carbon allocation dynamics. As a result, SLA is only marginally related to productivity (by determining the maximum amount of carbon that can be allocated) and is completely decoupled from phenology. As a consequence, the role of SLA on carbon fluxes is therefore limited compared to that of $V_{\mathrm{cmax}_{25}}$ and $J_{\max _{25}}$ (see, for a more detailed discussion, Verheijen et al., 2013).
The default model has been benchmarked against contemporary conditions (Brovkin et al., 2013; Dalmonech \& Zaehle, 2013). Verheijen et al. (2013) discussed the contemporary performance of the model when trait variation is included; GPP in the tropics was higher than in the default model, but it performed similarly well or better with respect to vegetation distribution and carbon pools.

\section{Selected data and trait-environment relationships}

The selected trait and climate data and the majority of the methods applied for determining the trait-environment relationships are described in detail in Verheijen et al. (2013). Briefly, data for SLA, $V_{\mathrm{cmax}_{25}}$, and $J_{\max _{25}}$ were obtained from the TRY database (Kattge et al., 2011), supplemented with SLA data from Van Bodegom et al. (2012) and $V_{\mathrm{cmax}_{25}}$ and $J_{\max _{25}}$ data from Domingues et al. (2010) (Table 1). For C4 grasses, PEP carboxylase $\mathrm{CO}_{2}$ specificity (PEP, $\mathrm{mmol} \mathrm{m} \mathrm{m}^{-2} \mathrm{~s}^{-1}$ ) instead of $J_{\max _{25}}$ was modeled. For this PFT, PEP and $V_{\mathrm{cmax}_{25}}$ data were very limited; therefore, these traits were estimated based on leaf nitrogen data from the TRY database and equations from Simioni et al. (2004). Every trait observation was assigned to a JSBACH PFT based on information about growth form, leaf habit, photosynthetic pathway, and occurrence in a climatic region of the Köppen-Geiger classification (Kottek et al., 2006). Community mean trait values were calculated for each PFT, weighted by square root of the number of observations per community. For SLA, this resulted in 1052 PFT-specific entries (12 394 observations over 2869 species), 70 entries for $V_{\mathrm{cmax}_{25}}$ (761 observations over 129 species), and 56 entries for $J_{\max _{25}}$ (402 observations over 108 species).

To define trait-environment relationships, community mean trait values were related to a set of environmental drivers. For each PFT, multiple linear regression was applied to combinations of climatic variables. For $\mathrm{CO}_{2}$, a separate regression was determined, because the response of plants to $\mathrm{CO}_{2}$ concentrations other than ambient atmospheric $\mathrm{CO}_{2}$ could only be derived from $\mathrm{CO}_{2}$ enrichment experiments. As a consequence, the established trait-environment relationships are composite regressions.

Most climate data were taken from 10-min gridded datasets from the Climatic Research Unit (CRU) (New et al., 2002),

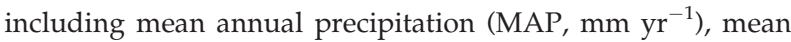

Table 1 References of selected trait data

\begin{tabular}{|c|c|}
\hline Trait & Reference \\
\hline SLA & $\begin{array}{l}\text { Ackerly \& Cornwell (2007), Bahn et al. (1999), Cavender-Bares et al. (2006), Cornelissen et al. (2003, 2004), Cornwell et al. } \\
\text { (2006), Fyllas et al. (2009), Garnier et al. (2007), Kattge et al. (2009, 2011), Kleyer et al. (2008), Kurokawa \& Nakashizuka } \\
\text { (2008), H. Kurokawa (unpublished data), Laughlin et al. (2010), M.R. Leishman (unpublished data), Louault et al. (2005), } \\
\text { Medlyn et al. (1999), Niinemets (1999, 2001), Ogaya \& Peñelas (2007, 2008), Ordoñez et al. (2010), Patino et al. (2012), } \\
\text { Pyankov et al. (1999), Reich et al. (2008, 2009), Shipley (1995), Shipley \& Vu (2002), N.A. Soudzilovskaia (unpublished } \\
\text { data), Swaine (2007), Van Bodegom et al. (2012), P.M. van Bodegom (unpublished data), Vile et al. (2006), E. Weiher } \\
\text { (unpublished data), Wohlfahrt et al. (1999) and Wright et al. (2004, 2006) }\end{array}$ \\
\hline$V_{\mathrm{cmax}_{25}}$ & Domingues et al. (2010), Kattge et al. (2009) and Niinemets $(1999,2001)$ \\
\hline$J_{\max _{25}}$ & Domingues et al. (2010) and Kattge et al. (2009) \\
\hline
\end{tabular}

SLA, specific leaf area. 
annual relative humidity (Reh, \%), mean annual temperature (MAT, ${ }^{\circ} \mathrm{C}$ ), and mean temperature of coldest and warmest month (Tmin and $\operatorname{Tmax},{ }^{\circ} \mathrm{C}$ ). In addition, annual soil moisture estimates (SoilMoist, $\mathrm{m}^{3} \mathrm{~m}^{-3}$ for 1 meter depth) were taken from a 15-min gridded datasets based on remotely sensed data (Miralles et al., 2011) and mean annual net shortwave radiation (NSWR, $\mathrm{W} \mathrm{m}^{-2}$ ) was calculated on a 30-min resolution following Allen et al. (1998) and based on CRU data on percentage sunshine.

These climatic variables were coupled to the PFT-specific trait means via georeferences. With the currently available metadata in TRY, it was not possible to link traits to the environmental conditions of the year the traits were measured. Instead, the mean of traits measured at different years was taken, assuming that they represented an 'average' year. All possible relationships were tested by multiple linear regression (including interactions). After checking for significance and colinearity of the environmental drivers and residual distribution, regressions with the highest $R_{\text {adjusted }}^{2}$ were selected. Due to the low number of entries for the two tropical tree PFTs and the two shrub PFTs, data were combined, resulting in two instead of four regressions for these PFTs. To prevent modeling unrealistic trait values, simulated traits were restrained to a $2.5-97.5 \%$ species-level quantile interval. Given that $V_{\mathrm{cmax}_{25}}$ and $J_{\max _{25}}$ are strongly correlated (Wullschleger, 1993), PFTspecific confidence intervals for their relationship were applied as an additional constraint.

In contrast to plant responses to climate, which could be based on field data, the response of plants to elevated $\mathrm{CO}_{2}$ concentrations could only be determined experimentally. For this, we used meta-analyses of $\mathrm{CO}_{2}$ enrichment experiments. Due to the relatively sparse data, some PFTs were grouped. For trees, the elevated $\mathrm{CO}_{2}$ responses of $V_{\mathrm{cmax}_{25}}$ and $J_{\max _{25}}$ were derived from the meta-analysis of Medlyn et al. (1999), and for shrubs and C3 grasses from Ainsworth \& Rogers (2007). C4 grasses did not show a significant response. For SLA, responses from Poorter et al. (2009) were taken for C3 (woody and nonwoody) plants and $\mathrm{C} 4$ plants. Elevated $\mathrm{CO}_{2}$ concentrations were approximately 700 ppm in Medlyn et al. (1999), on average $567 \mathrm{ppm}$ in Ainsworth \& Rogers (2007) and up to 1000 ppm in Poorter et al. (2009).

For C3 plants, the responses of PFTs to elevated $\mathrm{CO}_{2}$

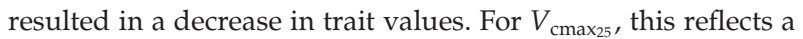
downregulation upon increasing $\mathrm{CO}_{2}$, caused by an increased affinity of Rubisco for $\mathrm{CO}_{2}$ at the expense of $\mathrm{O}_{2}$ affinity at higher internal $\mathrm{CO}_{2}$ concentrations (Leakey et al., 2012). In addition, there is less ATP needed for RuBP regeneration, allowing a reduction in $J_{\max _{25}}$ as well. Longer-term reduction in $V_{\mathrm{cmax}_{25}}$ is associated with a reduction in leaf nitrogen, which is re-allocated to other plant components to optimize carbon gain and resource use, especially within a nitrogen-limited environment (Ainsworth \& Long, 2005; Leakey et al., 2012). In addition, longer-term downregulation of photosynthesis is also associated with an increase in nonstructural carbohydrates like starch (Poorter et al., 2009; Leakey et al., 2012), explaining why SLA might decrease with increasing $\mathrm{CO}_{2}$ in C3 plants. In contrast, in C4 grasses, no change in SLA was found, the causes of which remain unclear (Poorter et al.,
2009). $V_{\mathrm{cmax}_{25}}$ and PEP did not show a strong response in C4 grasses, because these grasses have a $\mathrm{CO}_{2}$-concentrating mechanism leading to $\mathrm{CO}_{2}$ saturation rather independent from atmospheric $\mathrm{CO}_{2}$ concentrations (Poorter \& Navas, 2003). However, they can still benefit from higher atmospheric $\mathrm{CO}_{2}$ by an increased water-use efficiency via reduced stomatal conductance (Ainsworth \& Rogers, 2007).

The different regressions for $\mathrm{CO}_{2}$ and the climatic variables were combined (see Data S1 for a description of the regressions) and implemented in JSBACH. Trait values were calculated at the beginning of each simulated year, to allow simulation of trait values for the coming year based on the mean annual environmental conditions of the previous year for each PFT in each grid cell.

\section{Experimental design}

Four simulation experiments were carried out: two simulations with the default setup with the original default fixed trait values (DEF) and two including environment-driven variation in traits (VARTR). For each setup, one simulation with climate and atmospheric $\mathrm{CO}_{2}$ changes was run, allowing for $\mathrm{CO}_{2}$ fertilization effects on photosynthesis (called + fert) and one simulation with climate change but without $\mathrm{CO}_{2}$ fertilization (called -fert), by keeping atmospheric $\mathrm{CO}_{2}$ fixed at pre-industrial concentrations (atmospheric $\mathrm{CO}_{2}$ set at $284.7 \mathrm{ppm}$, approximately year 1850). In contrast to the DEF simulations, in both VARTR simulations, environmental change played an additional role in varying traits, although in VARTR-fert, the effect of $\mathrm{CO}_{2}$ on traits was constant over the years because $\mathrm{CO}_{2}$ was kept constant. With these simulations, interactions between trait variation and climate change (-fert) and the combined effects of both climate change and $\mathrm{CO}_{2}$ fertilization (+fert) on carbon fluxes could be investigated.

Simulations were performed with the MPI-ESM at a land resolution of $1.875^{\circ}$ (T63). Climate was internally simulated by the atmosphere model ECHAM6 (Stevens et al., 2013) and fluxes between land and atmosphere and vegetation dynamics by JSBACH. Seasonal sea surface temperatures and sea ice were prescribed and taken from simulations by fully coupled historical runs (1850-2004) and projections (2004-2100) from the C5MIP model intercomparison project following the RCP8.5 scenario (Van Vuuren et al., 2011). The same input of ozone, aerosols, and radiative forcing as in the C5MIP project was used, see Giorgetta et al. (2013) for an overview and description of sources. Only natural vegetation was modeled, and therefore, anthropogenic greenhouse gas emissions $\left(\mathrm{CO}_{2}\right.$, $\mathrm{N}_{2} \mathrm{O}, \mathrm{CH}_{4}$ and CFCs) were prescribed, following the RCP8.5 scenario as well, which implies a steady increase in atmospheric $\mathrm{CO}_{2}$ to $925.9 \mathrm{ppm}$ around 2100. The consequence of this prescribed atmospheric $\mathrm{CO}_{2}$ increase was that carbon feedbacks were not accounted for in the model.

Default simulations and simulations with variation in traits in PFTs had their own model initialization. For each model setup, the coupled JSBACH/ECHAM5 model was run until quasi-equilibrium (for the vegetation) for 250 years in the preindustrial climate by repeating 30 years of seasonal sea surface temperatures and sea ice forcing and running vegetation 
dynamics in an accelerated mode (where vegetation responses were simulated 3 times within each year). The last 30 years of this spin-up were used to drive the carbon balance model of JSBACH for 1500 years to get the soil carbon pools into equilibrium. Then the model was restarted with the equilibrated carbon pools and run for another 200 years (with vegetation dynamics in a normal mode) to get vegetation in equilibrium. The two different spin-ups were used to start the historical run and projections of the +fert and -fert simulations (i.e. $\mathrm{DEF}+$ fert and DEF-fert and VARTR+fert and VARTR-fert). This means the DEF and VARTR simulations had different initial climate and vegetation properties and carbon stocks, but + fert and -fert for either the DEF or the VARTR setup did not.

Simulations were performed till 2100 with $\mathrm{CO}_{2}$ concentrations increasing up to $\sim 925 \mathrm{ppm}$. For SLA, these concentrations fell within the calibration range of the meta-analysis, but maximum $\mathrm{CO}_{2}$ concentrations in the meta-analyses used to determine $V_{\mathrm{cmax}_{25}}$ and $J_{\max _{25}}$ responses to $\mathrm{CO}_{2}$ were on average lower. As a consequence, $\mathrm{CO}_{2}$ concentrations were outside the calibration range for grasses and shrubs for these traits from 2055 onward (i.e. above $567 \mathrm{ppm}$ ) and for trees from about 2073 onward (700 ppm). This means that results should be interpreted with care from 2055 onward, and especially the last quarter of the century should be considered speculative.

\section{Results}

\section{Contemporary estimates of carbon budgets}

The land carbon exchange, or net ecosystem exchange (NEE), of the variable traits simulation with both climate change and $\mathrm{CO}_{2}$ fertilization effects (VARTR+ fert) predicted a land carbon uptake in the 1980s, 1990s, and 2000s (Table 2, positive values mean land carbon uptake). These predictions fell within the $90 \%$ confidence interval of the global land carbon budget of the 1990s and 2000s, as estimated by the IPCC 2013 assessment (Ciais et al., 2013), whereas the default simulation (DEF+fert) only fell within the 1990s range. VARTR+fert

Table 2 Comparison of simulated global land carbon budgets (positive values mean land carbon uptake) with the estimates from the IPCC 2013 report (Ciais et al., 2013). Carbon in $\mathrm{Pg} \mathrm{C} \mathrm{yr}^{-1}$, in brackets the $90 \%$ confidence interval

\begin{tabular}{|c|c|c|c|}
\hline & \multirow{2}{*}{$\frac{1980 \mathrm{~s}}{\operatorname{Pg~C~yr}{ }^{-1}}$} & \multirow{2}{*}{$\frac{1990 \mathrm{~s}}{\mathrm{Pg} \mathrm{C} \mathrm{yr}}$} & \multirow{2}{*}{$\frac{2000 \mathrm{~s}}{\mathrm{Pg} \mathrm{C} \mathrm{yr}}$} \\
\hline & & & \\
\hline IPCC 2013 & $1.5(0.4-2.6)$ & $2.6(1.4-3.8)$ & $2.6(1.4-3.8)$ \\
\hline \multirow{2}{*}{\multicolumn{4}{|c|}{$\begin{array}{l}\text { Residual Land } \\
\text { Sink }\end{array}$}} \\
\hline & & & \\
\hline $\mathrm{DEF}+$ fert & 3.05 & 3.21 & 3.98 \\
\hline VARTR+fert & 2.89 & 2.4 & 3.49 \\
\hline $\mathrm{DEF}+$ fert & -0.94 & -0.55 & -1.29 \\
\hline VARTR-fert & -0.43 & -1.11 & -1.00 \\
\hline
\end{tabular}

DEF, default fixed trait values. had a lower NEE and was closer to the mean estimate than DEF+fert for either the 1980s, 1990s, or 2000s. Either simulation with climate change but without $\mathrm{CO}_{2}$ fertilization effects (DEF-fert and VARTR-fert) predicted a land carbon release for each of the contemporary time periods.

\section{Projected global NEE}

Both simulations with climate change and $\mathrm{CO}_{2}$ fertilization effects (DEF+fert and VARTR+fert) showed an increase in land carbon initially (Fig. 1), but NEE started to level off toward 2050 and showed a steady decline in NEE in the second half of the 21st century. Compared to the DEF+fert simulation, land in the VARTR+fert simulation was a weaker carbon sink (see also carbon pools in Fig. S1). Projected NEE was on average 2.1 $\mathrm{Pg} \mathrm{C} \mathrm{yr}^{-1}$ lower in the second and third quarters of the 21st century and $2.7 \mathrm{Pg} \mathrm{C} \mathrm{yr}^{-1}$ lower in the last quarter, which means, respectively, 33.0, 36.2, and $69.9 \%$ less carbon sequestration in VARTR+fert than in $\mathrm{DEF}+$ fert in these periods.

In the -fert simulations (DEF-fert and VARTRfert), the lack of $\mathrm{CO}_{2}$ fertilization on photosynthesis resulted in a steady weakening of the land carbon sink over time, because the increase in both autotrophic (Ra) and heterotrophic ( $\mathrm{Rh}$ ) respiration due to higher temperatures was not compensated by an increase in GPP, like in the +fert simulations (see Fig. S2 for separate fluxes). Land in the VARTR-fert was a stronger carbon source than in DEF-fert, although differences were smaller than between +fert simulations. NEE in

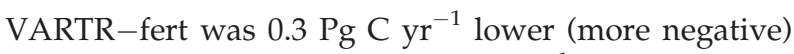
in the 2nd quarter and $1.0 \mathrm{Pg} \mathrm{C} \mathrm{yr}^{-1}$ lower in both the $3 \mathrm{rd}$ and 4 th quarter of the 21st century, which represented an increase in the carbon source of 11.1, 28.8 , and $21.7 \%$, respectively, compared to DEF-fert.

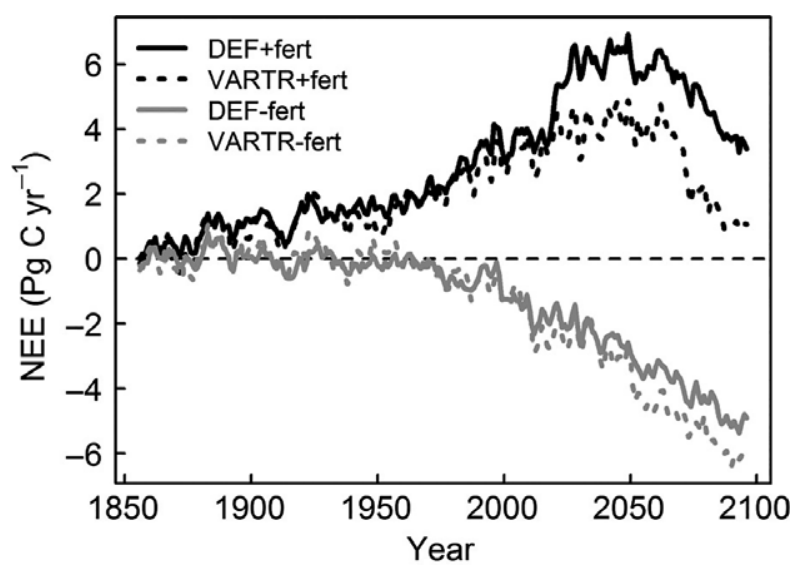

Fig. 1 Global net ecosystem exchange (10-year running mean in $\mathrm{Pg} C \mathrm{yr}^{-1}$ ). Positive values mean land carbon uptake. 

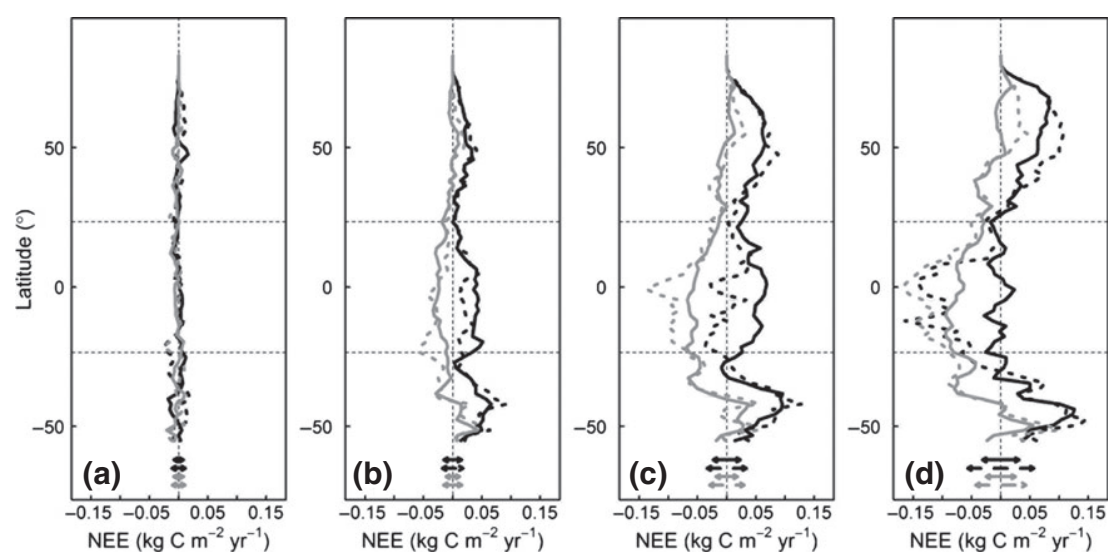

Fig. 2 Latitudinal gradients of (10-year mean) average net ecosystem exchange $\left(\mathrm{kg} \mathrm{C} \mathrm{m}^{-2} \mathrm{yr}^{-1}\right)$, with global standard deviations (bottom horizontal lines): (a) 1851, (b) 2000, (c) 2050, and (d) 2100. Legend as in Fig. 1. Horizontal dashed lines denote the Tropic of Cancer and Capricorn.

In VARTR, NEE differences between the (combined) effects of $\mathrm{CO}_{2}$ fertilization (+fert) and climate change vs. climate change alone (-fert) were 1.8, 1.0, and 1.7 $\mathrm{Pg} \mathrm{C} \mathrm{yr}^{-1}$ less in the last 3 quarters of the 21st century compared to differences between + fert and - fert in DEF. This means that by including trait variation, the (combined) effects of $\mathrm{CO}_{2}$ fertilization and climate change on the global carbon sink and source patterns were modified as well.

\section{Latitudinal changes in NEE}

Latitudinal NEE (Fig. 2) clarifies which areas contributed most to the changes in global NEE. For the contemporary climate, differences across latitudes and among simulations were small. However, over time, differences in latitudinal NEE between simulations became more profound, both in the amount of carbon sequestered or released and in the spatial distribution. In addition, global variability in NEE increased over time and was larger in VARTR than in DEF simulations (compare standard deviations in Fig. 2). From around 2050, NEE of the tropics (defined as area between the Tropic of Cancer and Tropic of Capricorn) started to diverge more strongly from NEE at the mid- and high latitudes (i.e. temperate, boreal, and arctic areas in the northern hemisphere) in VARTR simulations compared to the DEF simulations. This divergence was caused both by a stronger increase in carbon sequestration in the mid- and high latitudes and a stronger carbon release in the tropical areas in the VARTR simulations.

\section{Latitudinal changes in traits}

In general, latitudinal gradients of mean trait values averaged over all PFTs (and weighted by fractional cover of a PFT in a grid cell) showed a decreasing trend over time in VARTR+fert (Fig. 3), but in VARTR-fert, traits changed less and even increased in some areas (e.g. above $50^{\circ} \mathrm{N}$ ). In contrast, in both DEF simulations, shifts in traits were small, because weighted mean trait values in grid cells could only change with shifts in PFT cover. In all simulations, $V_{\mathrm{cmax}_{25}}$ and $J_{\max _{25}}$ were clearly lower in the tropics than at mid- and high latitudes, due to more favorable environmental conditions (e.g. higher temperatures and a longer growing season).

Variation in traits was induced by both changes in climatic drivers and $\mathrm{CO}_{2}$ in VARTR+fert. By removing the $\mathrm{CO}_{2}$-induced variation from the VARTR+fert trait values, trait changes over time (left to right panels) caused by climatic variables alone (blue line in Fig. 3) could be investigated. In addition, the difference between trait values based on all environmental drivers (black dashed line) and climatic drivers alone (blue line) reflects the amount of change induced by elevated $\mathrm{CO}_{2}$.

Climate-induced variation in PFT-averaged trait values resulted in trait patterns of VARTR+fert shifting strongly toward those of VARTR-fert (i.e. blue lines and gray dashed lines), where $\mathrm{CO}_{2}$ did not affect vegetation and traits thus varied in response to climate only. Trait values, however, did not completely overlap, reflecting trait-induced differences in climate and vegetation cover among the VARTR simulations. These climate-induced changes could both increase or decrease over time, depending on the dominant PFT (see also Fig. S3 for PFT-specific trait responses over time). In contrast, including the response of $\mathrm{CO}_{2}$ always resulted in a decrease in trait values (expect for SLA for C4 grasses). The net changes in traits depended on both the amount and direction of change induced by both climatic variables and $\mathrm{CO}_{2}$, which 

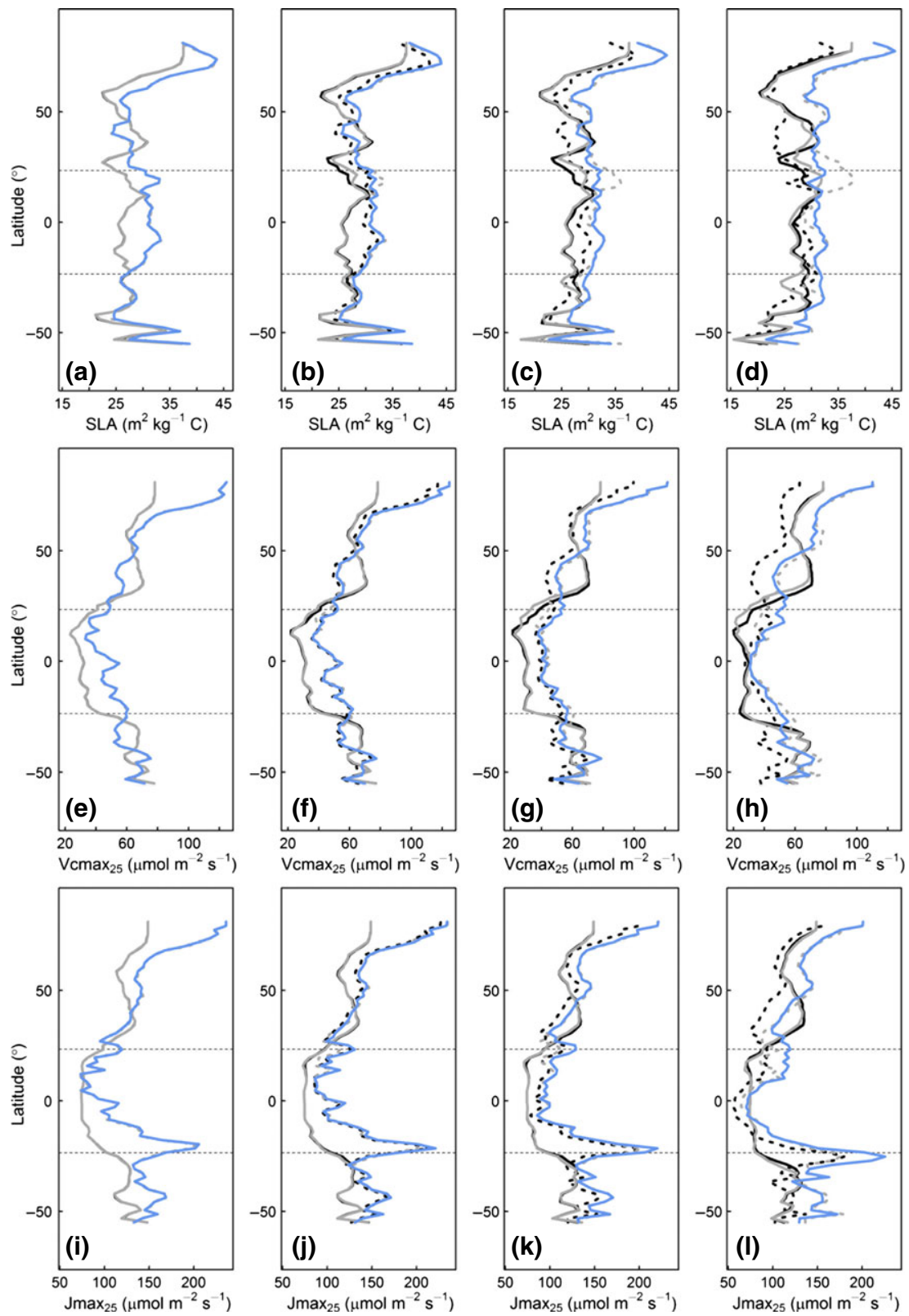

Fig. 3 Latitudinal gradients of (10-year mean) trait values, weighted by fractional plant functional types (PFT) cover: (a, e, i) 1851, (b,f, j) 2000, (c,g,k) 2050, and (d,h,l) 2100. Upper row, specific leaf area (SLA) $\left(\mathrm{kg} \mathrm{m}^{-2}\right)$; middle row, $V_{\mathrm{cmax}_{25}}\left(\mu \mathrm{mol} \mathrm{m}^{-2} \mathrm{~s}^{-1}\right)$; and lower row, $J_{\max _{25}}\left(\mu \mathrm{mol} \mathrm{m} \mathrm{m}^{-2} \mathrm{~s}^{-1}\right.$, without $\mathrm{C} 4$ grasses). Legend as in Fig. 1. In addition, blue line: VARTR+fert without $\mathrm{CO}_{2}$ response. Horizontal dashed lines denote the Tropic of Cancer and Capricorn. Note that in 1851, trait values within default fixed trait values (DEF) and VARTR overlap initially and therefore some simulations seem absent.

varied between PFTs (Fig. S3). The relative contribution of $\mathrm{CO}_{2}$ and climate to variation in traits was therefore also PFT dependent.

\section{Latitudinal changes in fluxes}

In the DEF+fert simulation, GPP steadily increased over time in mid- and high latitudes as well as the tropics, whereas in VARTR+fert, GPP started already to decline in the equatorial tropics in the 2nd quarter of the 21st century. Changes in traits affected GPP, but productivity in the +fert simulations was mostly determined by direct $\mathrm{CO}_{2}$ fertilization effects, because GPP still increased even when $V_{\text {cmax }_{25}}$ and $J_{\max _{25}}$ decreased (compare Figs 3 and 4). In most cases, when $V_{\mathrm{cmax}_{25}}$ and $J_{\max _{25}}$ dropped below values as prevailing in DEF+fert, this resulted in a lower GPP in VARTR+fert as well. 

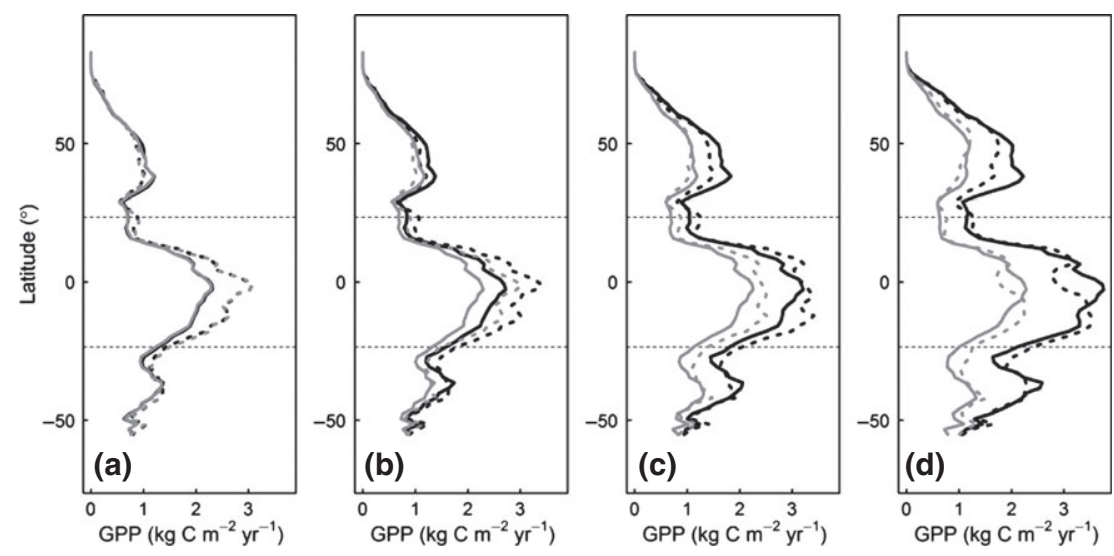

Fig. 4 Latitudinal gradients of (10-year mean) average annual gross primary productivity (GPP) (kg C m ${ }^{-2} \mathrm{yr}^{-1}$ ): (a) 1851, (b) 2000, (c) 2050, and (d) 2100. Legend as in Fig. 1. Horizontal dashed lines denote the Tropic of Cancer and Capricorn.

Overall, the NPP : GPP ratio (Fig. 5) was lower for all simulations in the tropics compared to the high latitudes, because higher temperatures enhance respiration in the tropics (Raddatz et al., 2007). Changes in this ratio were caused by direct $\mathrm{CO}_{2}$ fertilization effects and temperature effects on GPP and temperature effects on Ra. Changes in $V_{\text {cmax }_{25}}$ and $J_{\max _{25}}$ modified this ratio additionally, making it difficult to disentangle the relative contribution of each variable. Over time, the areas in the mid- and high latitudes where the NPP : GPP ratio was higher in VARTR+fert than in DEF+fert increased over time, indicating relatively lower respirational costs in VARTR+fert. Even though GPP was equal to or lower than in DEF+fert, this resulted in higher NEE in large parts of these regions from around 2050 onward in VARTR+fert. In contrast, in the tropics, the NPP : GPP ratio was almost always lower (meaning relatively higher respirational losses) in VARTR+fert, independent of whether GPP was lower or higher than in DEF+fert. Over time, Rh became slightly lower (Fig. S4) in VARTR+fert, but this could not compensate for the lower carbon use efficiency, and NEE dropped to negative values around 2050.

In the -fert simulations, these dynamics of fluxes and traits resulted in similar differences: a somewhat higher NEE for VARTR-fert at higher latitudes and lower NEE in the tropics compared to DEF-fert.

\section{Discussion}

Implications of trait variation for global and regional responses in carbon fluxes

In this study, we implemented trait variation within PFTs based on observed trait-environment relationships, allowing for variation in functional responses to changes in the environment within PFTs. This approach is a logical next step from using PFTs with static
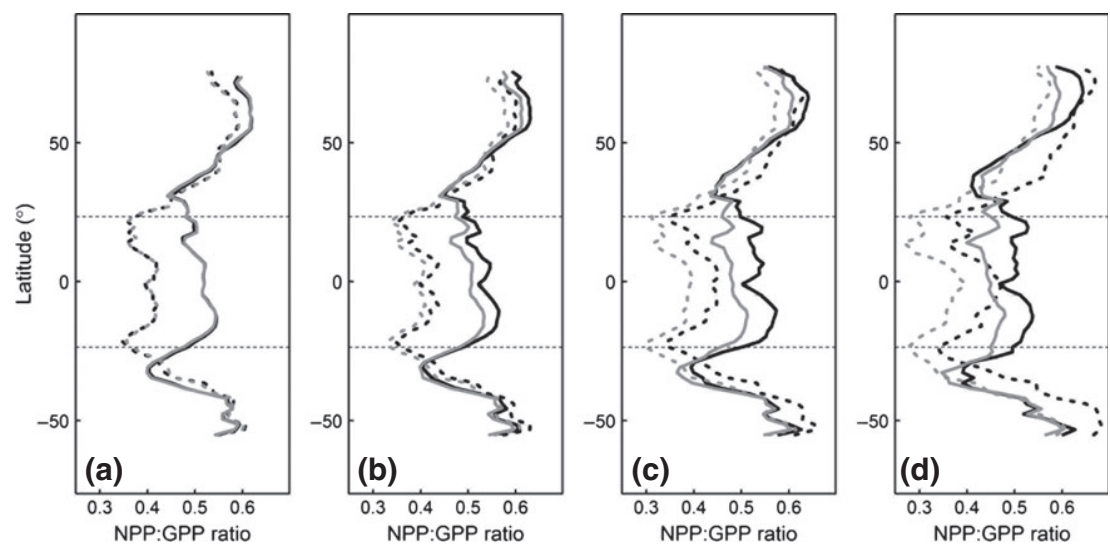

Fig. 5 Latitudinal gradients of (10-year mean) NPP : GPP ratios: (a) 1851, (b) 2000, (c) 2050, and (d) 2100. To prevent numeric artefacts, areas where gross primary productivity (GPP) is $<0.05$ are left out. Legend as in Fig. 1 . Horizontal dashed lines denote the Tropic of Cancer and Capricorn. 
properties, which hampers the modeling of more dynamic functional vegetation responses (Kattge et al., 2011; Van Bodegom et al., 2012; Pavlick et al., 2013). Allowing for a more realistic functional response of vegetation to environmental change by including trait variation allowed for better estimates of contemporary global land carbon uptake (Table 2) and altered global and regional source-sink patterns of carbon.

Even though the direct $\mathrm{CO}_{2}$ fertilization effect on GPP was more profound than the effect of trait variation on GPP (compare the change over time in GPP in VARTR+fert and VARTR-fert simulations), changes in traits modified GPP and affected NEE. This resulted in a lower NEE in VARTR+fert compared to DEF+fert of on average 2.1 $\mathrm{Pg} \mathrm{C} \mathrm{yr}^{-1}$ between 2026 and 2075 and

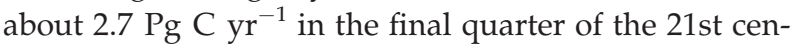
tury, although this last projection remains rather uncertain due to extrapolation of trait responses to elevation $\mathrm{CO}_{2}$ beyond the calibration range. Regionally, however, NEE also increased, particularly at the mid- and high latitudes. The strong reduction in NEE in VARTR+fert can mostly be attributed to the tropics, where predictions are relatively uncertain, as data availability for the calibration of trait-environment relationships was limited (see Materials and Methods section). The robustness of this outcome thus needs to be evaluated in future studies.

The actual effects of traits on model performance are difficult to pinpoint due to the different pathways by which variation in traits can cascade through the model. Changes in traits drive changes in GPP ( $V_{\mathrm{cmax}_{25}}$ and $\left.J_{\max _{25}}\right), R_{\mathrm{a}}\left(V_{\mathrm{cmax}_{25}}\right.$, via $\left.R_{\mathrm{d}, 25}\right)$ and carbon storage (SLA), and consequently modify carbon use efficiency via the NPP : GPP ratio. Moreover, the effects of changes in traits do not only work via modification in vegetation carbon fluxes, but also indirectly through effects on vegetation distribution (via NPP-induced shifts in competitive advantage), Rh (via litter quality and quantity), and feedbacks to climate (e.g. via changes in productivity or vegetation distribution, see Verheijen et al., 2013). These multiple pathways via which trait effects the carbon cycle can cascade through the system are probably the main cause for the modification of functional vegetation responses by variable traits to be strongly region dependent.

In addition, trait effects on vegetation and fluxes are not easy to disentangle from direct effects of changes in climate or $\mathrm{CO}_{2}$ fertilization effects. However, by comparing differences between $\mathrm{DEF}+$ fert and $\mathrm{DEF}$-fert with differences between VARTR+fert and VARTR-fert, it was possible to identify to which extent trait variation affected the (combined) effects of climate change and $\mathrm{CO}_{2}$ fertilization (+fert simulations) on global carbon sequestration compared to climate change effects alone (-fert simulations). Globally, this effect of variable traits (comparing +fert to -fert simulations) was substantial and dampened global carbon sequestration by on average $1.8 \mathrm{Pg} \mathrm{C} \mathrm{yr}^{-1}$ in the 2 nd quarter and 1.0 $\mathrm{Pg} \mathrm{C} \mathrm{yr}^{-1}$ and 1.7 $\mathrm{Pg} \mathrm{C} \mathrm{yr}^{-1}$ in the third and fourth quarter of the 21st century in VARTR compared to DEF. While the relative contribution of $\mathrm{CO}_{2}$ and climatic variables to variation in traits differed per PFT, $\mathrm{CO}_{2}$-induced trait responses consistently resulted in a decrease in global PFT-averaged trait values. In particular, for $V_{\mathrm{cmax}_{25}}$ and $J_{\max _{25}}$, this resulted in lower trait values and productivity, dampening the effect of $\mathrm{CO}_{2}$ fertilization on photosynthesis, and resulting in smaller differences between + fert and -fert in VARTR than in DEF.

Together, these results suggest that our model, but potentially other ESMs as well, currently overestimates projected land carbon uptake, which implies more $\mathrm{CO}_{2}$ than expected will stay airborne at the end of the 21st century.

\section{Challenges for including trait variation in DGVMs}

Due to gaps in current knowledge and available data, some uncertainties concerning the trait-environment relationships as applied in the current approach remain to be resolved. For some PFTs, the number of trait data was limited, and in some cases, the fraction of trait variance explained by environmental drivers was low (see Data S1). However, the established trait-environment relationships are based on community mean traits and thus less prone to biases caused by large differences in the number of observations for individual species.

In addition, the incorporated relationships are based on spatial patterns in trait-environment relations and subsequently applied to predict future temporal patterns in trait variation. The applicability of such relationships under future climate is uncertain, because $i$. acclimation and adaptation processes may affect traitenvironment relationships, ii. prevailing vegetation may lag in its response (Chapin \& Starfield, 1997) or may not respond in similar ways to imposed environmental changes as the responses inferred from community mean trait-environment relationships, and iii. the combination of future climate, atmospheric chemistry, and soil properties may lead to novel abiotic regimes and ecosystem types that cannot easily be predicted from knowledge about the present or past (Chapin \& Starfield, 1997; Reu et al., 2014).

Concerning the first point, the importance of and variation in trait acclimation and adaptation to environmental change are currently largely unknown at a global scale and can therefore not yet be quantitatively incorporated in DGVMs. For example, long-term 
temperature and $\mathrm{CO}_{2}$ acclimation of photosynthesis and temperature acclimation of respiration are lacking in most global models (Smith \& Dukes, 2013). In our model, vegetation acclimation and adaptation to elevated $\mathrm{CO}_{2}$ are based on measured PFT-specific responses, but measurements on vegetation responses to long-term $\mathrm{CO}_{2}$ enrichment treatments with very high concentrations of $\mathrm{CO}_{2}$ are still relatively scarce. Trait responses to environmental changes might be modified by interactions between $\mathrm{CO}_{2}$ and other environmental drivers, whereas our trait-environment regressions are composite additive regressions. However, long-term studies (spanning several growing seasons) investigating such interactions on plant performance are still limited, and interactions do not always occur (as, e.g. between $\mathrm{CO}_{2}$, temperature, and drought, Kongstad et al., 2012; Arndal et al., 2014) or show idiosyncratic responses (e.g. for the interactive effect between $\mathrm{CO}_{2}$ and nitrogen, see Norby \& Zak (2011) for an overview). In addition, trait responses to $\mathrm{CO}_{2}$ are very likely to change with increasing atmospheric $\mathrm{CO}_{2}$, because these trait changes do not stand alone from other physiological processes, such as reductions in stomatal conductance, nitrogen re-allocation, and accumulation of sugars (Leakey et al., 2012), all of which can modulate the response of $V_{\mathrm{cmax}_{25}}$ and $J_{\max _{25}}$ to $\mathrm{CO}_{2}$. Due to data limitations, however, a more sophisticated modeling of the actual responses of these traits beyond assuming a linear response was currently out of reach. Because of these uncertainties in adaptive and interactive responses, results after 2050 need to be interpreted with care, also because $V_{\operatorname{cmax}_{25}}$ and $J_{\max _{25}}$ responses to $\mathrm{CO}_{2}$ concentrations are outside the range of the meta-analysis for shrubs and grasses from 2055 onward (i.e. above $567 \mathrm{ppm})$, even though for trees, these responses are still within the calibration range till about 2073 and SLA responses can be extrapolated to the end of the century.

With respect to the second uncertainty, it appears that the observed intra- and interannual variation in LMA (leaf mass per area, inverse of SLA) of oaks and perennial grasses (6-year time span) (Ma et al., 2011) and $V_{\mathrm{cmax}_{25}}$ in oak and ash (3-year time span) (Grassi et al., 2005) is as strong as the simulated variation in the traits of deciduous trees or $\mathrm{C} 3$ grasses over a period of 250 years. This demonstrates the huge amount of variation in leaf traits possible within only a few years and shows the responsiveness of vegetation to changing environmental conditions. Moreover, over a 250-year time period (the length of the simulations), variation in functional vegetation responses of nonwoody vegetation (in much lesser amount in woody vegetation due to longer turnover times) might additionally be driven by genetic adaptation or shifts in species abundance.
Thus, although the use of trait-environmental relationships has its limitations for applications in global modeling, its inclusion allows accounting for variation in traits within PFTs within realistic ranges, which have been shown to be very large.

Concerning the last point, moving away from PFTs toward a completely traits-based modeling approach can allow for nonanalogue vegetation types (Van Bodegom et al., 2012; Reu et al., 2014). In our model, we set additional limits on traits to prevent unrealistic trait ranges outside observed ranges. Therefore, we may have conservatively assessed the impacts of potential nonanalogue conditions.

In addition to these uncertainties concerning data availability and knowledge gaps about vegetation responses, the model design also poses limitations on the implementation of trait variation. Plant traits are often correlated, and we accounted for such trade-offs for $V_{\mathrm{cmax}_{25}}$ and $J_{\max _{25} \text {. However, well-known trade-offs }}$ from the 'leaf economics spectrum' (Wright et al., 2004), for example, between SLA and these photosynthetic traits or leaf life span (LLS), could not be implemented because in JSBACH, phenology is modeled independently from productivity and carbon storage. Hence, in contrast to many DGVMs, in JSBACH, SLA is not linking productivity and LAI. This decoupling of SLA makes trade-offs with photosynthetic traits and LLS less relevant, although in other vegetation models with a more central role for SLA, such trade-offs are necessary. For a more elaborate discussion on this, we refer to Verheijen et al. (2013).

\section{Toward a more realistic vegetation representation by including an integrated estimate of trait variation}

A number of alternative approaches have been developed to realize more (trait) variation in vegetation models, from realizing trait variation as an emergent property based on fundamental trade-offs (Pavlick et al., 2013; Scheiter et al., 2013) to data-driven approaches based on observed species trait values (Fyllas et al., 2014). So far, none of these approaches use integrated estimates of community-level trait variation by linking observational trait data to multiple environmental drivers. Community mean trait responses include both within-species acclimation or adaptation as well as changes in trait values caused by shifts in species abundances as a consequence of competition or environment-induced mortality. Both components need to be considered given that single species responses do not necessarily translate to responses at the community level (Poorter \& Navas, 2003). Moreover, the combination of responses also implies that trait responses will not automatically result in biomass increment in a 
community. For example, at the end of the 21st century, there was a drop in the productivity of tropical forests in the VARTR+fert simulation, whereas GPP kept increasing in $\mathrm{DEF}+$ fert. This makes it very difficult to predict the direction of change in carbon fluxes $a$ priori.

In addition, by empirically including multiple environmental drivers, various sources of trait variation were captured. Due to model limitations, edaphic drivers such as nitrogen and phosphorus availability or soil age and structure are still lacking. Indirectly though, at least nutrient limitation is partially covered by the inclusion of vegetation responses to elevated $\mathrm{CO}_{2}$, because nutrient limitation may arise when vegetation is exposed to higher $\mathrm{CO}_{2}$ for longer time periods (Reich et al., 2006; Norby et al., 2010). This means that in the VARTR+fert simulation, predictions are more conservative than in the DEF simulation (without any nutrients constraints at all), in results are in line with JSBACH simulations with $\mathrm{N}$ and $\mathrm{P}$ cycling, where projected land carbon uptake is reduced due to lower productivity caused by nutrient limitations (Goll et al., 2012).

Together, with our approach, a more realistic response of vegetation to changing environmental conditions, by allowing for both spatial and temporal trait variation within PFTs, can be implemented in ESMs. To further study these responses, we propose i. further development of trait databases to improve the reliability of the vegetation responses to changing climate, ii. inclusion of our approach within other DGVMs, and iii. further development of completely traits-based DGVMs. In our case, an integral assessment of these modifications in the carbon cycle through functional vegetation responses has already revealed substantial impacts on global and regional fluxes.

\section{Acknowledgements}

This study has been financed by the Netherlands Organization for Scientific Research (NWO), Theme Sustainable Earth Research (project number TKS09-03). The authors are grateful to the TRY initiative on plant traits (http://www.try-db.org). TRY is hosted, developed, and maintained at the Max Planck Institute for Biogeochemistry, Jena, Germany, and is or has been supported by DIVERSITAS, IGBP, the Global Land Project, QUEST, and GIS 'Climat, Environnement et Société' France. Finally, the authors thank Veronika Gayler (Max Planck Institute for Meteorology, Hamburg, Germany) for the technical and methodological support on the projections and Marjan van de Weg (Abertay University, Dundee, UK) for her help on interpreting $V_{\mathrm{cmax}_{25}}$ responses.

\section{References}

Ackerly DD, Cornwell WK (2007) A trait-based approach to community assembly: partitioning of species trait values into within- and among-community components. Ecology Letters, 10, 135-145.
Ainsworth EA, Long SP (2005) What have we learned from 15 years of free-air $\mathrm{CO}_{2}$ enrichment (FACE)? A meta-analytic review of the responses of photosynthesis, canopy. New Phytologist, 165, 351-371.

Ainsworth EA, Rogers A (2007) The response of photosynthesis and stomatal conductance to rising $\left[\mathrm{CO}_{2}\right]$ : mechanisms and environmental interactions. Plant Cell and Environment, 30, 258-270.

Allen RG, Pereira LS, Raes D, Smith M (1998) Crop Evapotranspiration - Guidelines for Computing Crop Water Requirements - FAO Irrigation and Drainage Paper 56. Food and Agriculture Organization of the United Nations, Rome.

Arndal MF, Schmidt IK, Kongstad J, Beier C, Michelsen A (2014) Root growth and N dynamics in response to multi-year experimental warming, summer drought and elevated $\mathrm{CO}_{2}$ in a mixed heathland-grass ecosystem. Functional Plant Biology, 41 $1-10$.

Bahn M, Wohlfahrt G, Haubner E (1999) Leaf photosynthesis, nitrogen contents and specific leaf area of 30 grassland species in differently managed mountain ecosystems in the Eastern Alps. In: Land-Use Changes in European Mountain Ecosystems. ECOMONT - Concepts and Results (eds Cernusca A, Tappeiner U, Bayfield N), pp. 247-255. Berlin, Blackwell, Wissenschaft.

Brovkin V, Raddatz T, Reick CH, Claussen M, Gayler V (2009) Global biogeophysical interactions between forest and climate. Geophysical Research Letters, 36, L07405.

Brovkin V, Boysen L, Raddatz T, Gayler V, Loew A, Claussen M (2013) Evaluation of vegetation cover and land-surface albedo in MPI-ESM CMIP5 simulations. Journal of Advances in Modeling Earth Systems, 5, 48-57.

Cavender-Bares J, Keen A, Miles B (2006) Phylogenetic structure of floridian plant communities depends on taxonomic and spatial scale. Ecology, 87, S109-S122.

Chapin FS, Starfield AM (1997) Time lags and novel ecosystems in response to transient climatic change in arctic Alaska. Climatic Change, 35, 449-461.

Ciais P, Sabine C, Bala G et al. (2013) Carbon and other biogeochemical cycles. In: Climate Change 2013: The Physical Science Basis. Contribution of Working Group 1 to the Fifth Assessment Report of the Intergovernmental Panel on Climate Change (eds Stocker TF, Qin D, Plattner G-K, Tignor M, Allen SK, Boschung J, Nauels A, Xia Y, Bex V, Midgley PM), pp. 465-570. Cambridge University Press, Cambridge, UK, New York, NY, USA

Collatz GJ, Ribas-Carbo M, Berry JA (1992) Coupled photosynthesis-stomatal conductance model for leaves of $\mathrm{C}_{4}$ plants. Australian Journal of Plant Physiology, 19, 519-538.

Cornelissen JHC, Cerabolini B, Castro-Diez P et al. (2003) Functional traits of woody plants: correspondence of species rankings between field adults and laboratorygrown seedlings? Journal of Vegetation Science, 14, 311-322.

Cornelissen JHC, Quested HM, Gwynn-Jones D et al. (2004) Leaf digestibility and litter decomposability are related in a wide range of subarctic plant species and types. Functional Ecology, 18, 779-786.

Cornwell WK, Schwilk DW, Ackerly DD (2006) A trait-based test for habitat filtering: Convex hull volume. Ecology, 87, 1465-1471.

Dalmonech D, Zaehle S (2013) Towards a more objective evaluation of modelled land-carbon trends using atmospheric $\mathrm{CO}_{2}$ and satellite-based vegetation activity observations. Biogeosciences, 10, 4189-4210.

Diaz S, Hodgson JG, Thompson K et al. (2004) The plant traits that drive ecosystems: evidence from three continents. Journal of Vegetation Science, 15, 295-304.

Domingues TF, Meir P, Feldpausch TR et al. (2010) Co-limitation of photosynthetic capacity by nitrogen and phosphorus in West Africa woodlands. Plant Cell and Environment, 33, 959-980.

Douma JC, Aerts R, Witte JPM, Bekker RM, Kunzmann D, Metselaar K, Van Bodegom PM (2012a) A combination of functionally different plant traits provides a means to quantitatively predict a broad range of species assemblages in NW Europe. Ecography, 35, 364-373.

Douma JC, Witte J-PM, Aerts R et al. (2012b) Towards a functional basis for predicting vegetation patterns; incorporating plant traits in habitat distribution models Ecography, 35, 294-305.

Farquhar GD (1988) Models relating subcellular effects of temperature to whole plant responses. In: Plants and Temperature (eds Long SP, Woodward FI), pp. 395-409. Biologists Limited, Cambridge, UK.

Farquhar GD, Caemmerer SV, Berry JA (1980) A biochemical model of photosynthetic $\mathrm{CO}_{2}$ assimilation in leaves of $\mathrm{C}_{3}$ species. Planta, 149, 78-90.

Fyllas NM, Patino S, Baker TR et al. (2009) Basin-wide variations in foliar properties of Amazonian forest: phylogeny, soils and climate. Biogeosciences, 6, 2677-2708.

Fyllas NM, Gloor E, Mercado LM et al. (2014) Analysing Amazonian forest productivity using a new individual and trait-based model (TFS v. 1). Geoscientific Model Development Discussions, 7, 1251-1269.

Garnier E, Lavorel S, Ansquer P et al. (2007) Assessing the effects of land-use change on plant traits, communities and ecosystem functioning in grasslands: a 
standardized methodology and lessons from an application to 11 European sites. Annals of Botany, 99, 967-985.

Giorgetta MA, Jungclaus J, Reick CH et al. (2013) Climate and carbon cycle changes from 1850 to 2100 in MPI-ESM simulations for the Coupled Model Intercomparison Project phase 5. Journal of Advances in Modeling Earth Systems, 5, 572-597.

Goll DS, Brovkin V, Parida BR et al. (2012) Nutrient limitation reduces land carbon uptake in simulations with a model of combined carbon, nitrogen and phosphorus cycling. Biogeosciences, 9, 3547-3569.

Gotzenberger L, De Bello F, Brathen KA et al. (2012) Ecological assembly rules in plant communities-approaches, patterns and prospects. Biological Reviews, 87, 111-127.

Grassi G, Vicinelli E, Ponti F, Cantoni L, Magnani F (2005) Seasonal and interannual variability of photosynthetic capacity in relation to leaf nitrogen in a deciduous forest plantation in northern Italy. Tree Physiology, 25, 349-360.

Groenendijk M, Dolman AJ, Van Der Molen MK et al. (2011) Assessing parameter variability in a photosynthesis model within and between plant functional types using global Fluxnet eddy covariance data. Agricultural and Forest Meteorology, 151, 22-38.

Jones C, Robertson E, Arora V et al. (2013) Twenty-first-century compatible $\mathrm{CO}_{2}$ emissions and airborne fraction simulated by CMIP5 earth system models under four representative concentration pathways. Journal of Climate, 26, 4398-4413.

Kattge J, Knorr W, Raddatz T, Wirth C (2009) Quantifying photosynthetic capacity and its relationship to leaf nitrogen content for global-scale terrestrial biosphere models. Global Change Biology, 15, 976-991.

Kattge J, Diaz S, Lavorel S et al. (2011) TRY - a global database of plant traits. Global Change Biology, 17, 2905-2935

Keddy PA (1992) Assembly and response rules: two goals for predictive community ecology. Journal of Vegetation Science, 3, 157-164.

Kleyer M, Bekker RM, Knevel IC et al. (2008) The LEDA Traitbase: a database of lifehistory traits of the Northwest European flora. Journal of Ecology, 96, 1266-1274.

Kongstad J, Schmidt IK, Riis-Nielsen T, Arndal MF, Mikkelsen TN, Beier C (2012) High resilience in heathland plants to changes in temperature, drought, and $\mathrm{CO}_{2}$ in combination: results from the CLIMAITE experiment. Ecosystems, 15, 269-283.

Kottek M, Grieser J, Beck C, Rudolf B, Rubel F (2006) World map of the Köppen-Geiger climate classification updated. Meteorologische Zeitschrift, 15, 259-263.

Kurokawa H, Nakashizuka T (2008) Leaf herbivory and decomposability in a Malaysian tropical rain forest. Ecology, 89, 2645-2656.

Laughlin DC, Leppert JJ, Moore MM, Sieg CH (2010) A multi-trait test of the leafheight-seed plant strategy scheme with 133 species from a pine forest flora. Functional Ecology, 24, 493-501.

Lavorel S, Garnier E (2002) Predicting changes in community composition and ecosystem functioning from plant traits: revisiting the Holy Grail. Functional Ecology, 16, 545-556.

Leakey ADB, Ainsworth EA, Bernacchi CJ, Zhu X, Long SP, Ort DR (2012) Photosynthesis in a $\mathrm{CO}_{2}$-rich atmosphere. In: Photosynthesis. Plastid Biology, Energy Conservation and Carbon Assimilation. (eds Eaton-Rye JJ, Tripathy BC, Sharkey TD), pp. 733-768, Springer, Dordrecht.

Louault F, Pillar VD, Aufrere J, Garnier E, Soussana JF (2005) Plant traits and functional types in response to reduced disturbance in a semi-natural grassland. Journal of Vegetation Science, 16, 151-160.

Ma S, Baldocchi DD, Mambelli S, Dawson TE (2011) Are temporal variations of leaf traits responsible for seasonal and inter-annual variability in ecosystem $\mathrm{CO}_{2}$ exchange? Functional Ecology, 25, 258-270.

Medlyn BE, Badeck FW, De Pury DGG et al. (1999) Effects of elevated $\left[\mathrm{CO}_{2}\right]$ on photosynthesis in European forest species: a meta-analysis of model parameters. Plant Cell and Environment, 22, 1475-1495.

Miralles DG, Holmes TRH, RaM De Jeu, Gash JH, Meesters AGCA, Dolman AJ (2011) Global land-surface evaporation estimated from satellite-based observations. Hydrology and Earth System Sciences, 15, 453-469.

New M, Lister D, Hulme M, Makin I (2002) A high-resolution data set of surface climate over global land areas. Climate Research, 21, 1-25.

Niinemets U (1999) Components of leaf dry mass per area - thickness and density alter leaf photosynthetic capacity in reverse directions in woody plants. New Phytologist, 144, 35-47.

Niinemets U (2001) Global-scale climatic controls of leaf dry mass per area, density, and thickness in trees and shrubs. Ecology, 82, 453-469.

Norby RJ, Zak DR (2011) Ecological lessons from free-air $\mathrm{CO}_{2}$ enrichment (FACE) experiments. Annual Review of Ecology, Evolution, and Systematics, 42, 181-203.

Norby RJ, Warren JM, Iversen CM, Medlyn BE, Mcmurtrie RE (2010) $\mathrm{CO}_{2}$ enhancement of forest productivity constrained by limited nitrogen availability. Proceedings of the National Academy of Sciences of the United States of America, 107, 19368-19373.
Ogaya R, Peñuelas J (2007) Tree growth, mortality, and above-ground biomass accumulation in a holm oak forest under a five-year experimental field drought. Plant Ecology, 189, 291-299.

Ogaya R, Peñuelas J (2008) Changes in leaf $\delta^{13} \mathrm{C}$ and $\delta^{15} \mathrm{~N}$ for three Mediterranean tree species in relation to soil water availability. Acta Oecologica, 34, 331-338.

Ordoñez JC, Van Bodegom PM, Witte J-PM, Wright IJ, Reich PB, Aerts R (2009) A global study of relationships between leaf traits, climate and soil measures of nutrient fertility. Global Ecology and Biogeography, 18, 137-149.

Ordoñez JC, Van Bodegom PM, Witte J-PM, Bartholomeus RP, Van Hal JR, Aerts R (2010) Plant strategies in relation to resource supply in mesic to wet environments: does theory mirror nature? TheAmerican Naturalist, 175, 225-239.

Patino S, Fyllas NM, Baker TR et al. (2012) Coordination of physiological and structural traits in Amazon forest trees. Biogeosciences, 9, 775-801.

Pavlick R, Drewry DT, Bohn K, Reu B, Kleidon A (2013) The Jena Diversity-Dynamic Global Vegetation Model (JeDi-DGVM): a diverse approach to representing terrestrial biogeography and biogeochemistry based on plant functional trade-offs. Biogeosciences, 10, 4137-4177.

Poorter $\mathrm{H}$, Navas ML (2003) Plant growth and competition at elevated $\mathrm{CO}_{2}$ : on winners, losers and functional groups. New Phytologist, 157, 175-198.

Poorter H, Niinemets U, Poorter L, Wright IJ, Villar R (2009) Causes and consequences of variation in leaf mass per area (LMA): a meta-analysis. New Phytologist, 182, 565-588.

Poulter B, Hattermann F, Hawkins E et al. (2010) Robust dynamics of Amazon dieback to climate change with perturbed ecosystem model parameters. Global Change Biology, 16, 2476-2495

Pyankov VI, Kondratchuk AV, Shipley B (1999) Leaf structure and specific leaf mass: the alpine desert plants of the Eastern Pamirs, Tadjikistan. New Phytologist, 143, 131-142.

Raddatz TJ, Reick CH, Knorr W et al. (2007) Will the tropical land biosphere dominate the climate-carbon cycle feedback during the twenty-first century? Climate Dynamics, 29, 565-574

Reich PB, Hobbie SE, Lee T et al. (2006) Nitrogen limitation constrains sustainability of ecosystem response to $\mathrm{CO}_{2}$. Nature, 440, 922-925.

Reich PB, Tjoelker MG, Pregitzer KS, Wright IJ, Oleksyn J, Machado J-L (2008) Scaling of respiration to nitrogen in leaves, stems and roots of higher land plants. Ecology Letters, 11, 793-801.

Reich PB, Oleksyn J, Wright IJ (2009) Leaf phosphorus influences the photosynthesisnitrogen relation: a cross-biome analysis of 314 species. Oecologia, 160, 207-212.

Reick CH, Raddatz T, Brovkin V, Gayler V (2013) Representation of natural and anthropogenic land cover change in MPI-ESM. Journal of Advances in Modeling Earth Systems, 5, 459-482.

Reu B, Zaehle S, Bohn K, Pavlick R, Schmidtlein S, Williams JW, Kleidon A (2014) Future no-analogue vegetation produced by no-analogue combinations of temperature and insolation. Global Ecology and Biogeography, 23, 156-167.

Scheiter S, Langan L, Higgins SI (2013) Next-generation dynamic global vegetation models: learning from community ecology. New Phytologist, 198, 957-969.

Shaw RG, Etterson JR (2012) Rapid climate change and the rate of adaptation: insight from experimental quantitative genetics. New Phytologist, 195, 752-765.

Shipley B (1995) Structured interspecific determinants of specific leaf area in 34 species of herbaceous angiosperms. Functional Ecology, 9, 312-319.

Shipley B, Vu TT (2002) Dry matter content as a measure of dry matter concentration in plants and their parts. New Phytologist, 153, 359-364.

Simioni G, Le Roux X, Gignoux J, Walcroft AS (2004) Leaf gas exchange characteristics and water- and nitrogen-use efficiencies of dominant grass and tree species in a West African savanna. Plant Ecology, 173, 233-246.

Sitch S, Huntingford C, Gedney N et al. (2008) Evaluation of the terrestrial carbon cycle, future plant geography and climate-carbon cycle feedbacks using five Dynamic Global Vegetation Models (DGVMs). Global Change Biology, 14, 2015-2039

Smith NG, Dukes JS (2013) Plant respiration and photosynthesis in global-scale models: incorporating acclimation to temperature and $\mathrm{CO}_{2}$. Global Change Biology, 19, 45-63.

Stevens B, Giorgetta M, Esch M et al. (2013) Atmospheric component of the MPI-M Earth System Model: ECHAM6. Journal of Advances in Modeling Earth Systems, 5, $146-172$

Swaine EK (2007) Ecological and evolutionary drivers of plant community assembly in a Bornean rain forest. PhD thesis, University of Aberdeen, Aberdeen.

Van Bodegom PM, Douma JC, Witte JPM, Ordoñez JC, Bartholomeus RP, Aerts R (2012) Going beyond limitations of plant functional types when predicting global ecosystem-atmosphere fluxes: exploring the merits of traits-based approaches. Global Ecology and Biogeography, 21, 625-636. 
Van Bodegom PM, Douma JC, Verheijen LM (2014) A fully traits-based approach to modeling global vegetation distribution. Proceedings of the National Academy of Sciences of the United States of America, 111, 13733-13738.

Van Ommen Kloeke AEE, Douma JC, Ordoñez JC, Reich PB, Van Bodegom PM (2012) Global quantification of contrasting leaf life span strategies for deciduous and evergreen species in response to environmental conditions. Global Ecology and Biogeography, 21, 224-235.

Van Vuuren DP, Edmonds J, Kainuma M et al. (2011) The representative concentration pathways: an overview. Climatic Change, 109, 5-31.

Verheijen LM, Brovkin V, Aerts R et al. (2013) Impacts of trait variation through observed trait-climate relationships on performance of an Earth system model: a conceptual analysis. Biogeosciences, 10, 5497-5515.

Vile D, Shipley B, Garnier E (2006) Ecosystem productivity can be predicted from potential relative growth rate and species abundance. Ecology Letters, 9, 1061-1067.

White MA, Thornton PE, Running SW, Nemani RR (2000) Parameterization and sensitivity analysis of the BIOME-BGC terrestrial ecosystem model: net primary production controls. Earth Interactions, 4, 1-85.

Wohlfahrt G, Bahn M, Haubner E et al. (1999) Inter-specific variation of the biochemical limitation to photosynthesis and related leaf traits of 30 species from mountain grassland ecosystems under different land use. Plant Cell and Environment, 22, 1281-1296.

Wright IJ, Reich PB, Westoby M et al. (2004) The worldwide leaf economics spectrum. Nature, 428, 821-827.

Wright IJ, Reich PB, Cornelissen JHC et al. (2005) Modulation of leaf economic traits and trait relationships by climate. Global Ecology and Biogeography, 14, 411-421.

Wright IJ, Reich PB, Atkin OK, Lusk CH, Tjoelker MG, Westoby M (2006) Irradiance, temperature and rainfall influence leaf dark respiration in woody plants: evidence from comparisons across 20 sites. New Phytologist, 169, 309-319.
Wullschleger SD (1993) Biochemical limitations to carbon assimilation in $C_{3}$ plants - a retrospective analysis of the $A / C_{i}$ curves from 109 species. Journal of Experimental Botany, 44, 907-920.

Zaehle S, Sitch S, Smith B, Hatterman F (2005) Effects of parameter uncertainties on the modeling of terrestrial biosphere dynamics. Global Biogeochemical Cycles, 19, 1 16.

\section{Supporting Information}

Additional Supporting Information may be found in the online version of this article:

Data S1. Description of trait-environment relationships.

Figure S1. Time-series of changes in global carbon pools.

Figure S2. Time-series of changes in global mean carbon fluxes.

Figure S3. Latitudinal gradients of PFT-averaged traits.

Figure S4. Latitudinal gradients of mean annual heterotrophic respiration. 